\title{
SÍNTESE DE BETA FOSFATO TRICÁLCICO, POR REAÇÃO DE ESTADO SÓLIDO, PARA USO BIOMÉDICO
}

\author{
T. C. S. PEREIRA ${ }^{1}$, G. R. SANTOS ${ }^{1}$ e G. A. FERNANDES ${ }^{1}$ \\ ${ }^{1}$ Universidade Federal de Itajubá, Instituto de Engenharia Mecânica \\ E-mail para contato: thaticsp_ita@hotmail.com
}

\begin{abstract}
RESUMO - O beta fosfato tricálcico ( $\beta$-TCP) é uma cerâmica que apresenta uma composição química semelhante à composição do tecido ósseo, sendo por isso frequentemente empregado como biomaterial capaz de promover a ósteointegração. O $\beta$-TCP pode ser sintetizado a partir de diferentes métodos e existem diversas variáveis em cada método, como por exemplo, a temperatura de calcinação. Neste trabalho escolheu-se o método por reação de estado sólido, por ser relativamente simples e por utilizar matérias-primas baratas. Os reagentes, carbonato de cálcio e fosfato bibásico de cálcio foram misturados em acetona e secados em uma estufa. Amostras dessa mistura foram sinterizadas a $950 \mathrm{e}$ $1050^{\circ} \mathrm{C}$. O $\beta$-TCP obtido foi então caracterizado pelos métodos de difração de raios $\mathrm{X}$ (DRX) e espectroscopia na região do infravermelho com transformada de Fourier (FTIR). O FTIR mostrou a formação do fosfato e o desaparecimento do carbonato com o aumento da temperatura de sinterização. O DRX mostrou a formação das estruturas cristalinas presentes no $\beta$-TCP e confirmou a importância da sinterização, pelo ao aumento da cristalinidade com o aumento da temperatura. O método utilizado produziu o $\beta$-TCP com impurezas principalmente na amostra sinterizada a $950^{\circ} \mathrm{C}$.
\end{abstract}

\section{INTRODUÇÃO}

$\mathrm{O}$ beta fosfato tricálcico $(\beta-\mathrm{TCP})$, cuja fórmula química é $\beta-\mathrm{Ca}_{3}\left(\mathrm{PO}_{4}\right)_{2}$, é uma cerâmica de fosfato de cálcio que vem recebendo grande destaque no ramo biomédico (Gouveia, 2008). O $\beta$-TCP é uma fase de temperatura alta e é a fase com maior probabilidade de resultados satisfatórios no desenvolvimento de implantes biocerâmicos dentre as três fases polimorfas do fosfato tricálcico $\left(\beta, \alpha\right.$ e $\left.\alpha^{\prime}\right)$, pois possui melhor estabilidade química e resistência mecânica de acordo com Ryu et al (2002).

Apenas em temperaturas muito altas (superiores a $800^{\circ} \mathrm{C}$ ), através da decomposição térmica de hidroxiapatita deficiente em cálcio, este material pode ser preparado. Ou então, o $\beta$-TCP pode ser sintetizado pela interação no estado sólido de ortofosfato de cálcio acidificado (Zavaglia, 2011) segundo a equação abaixo:

$$
\mathrm{CaCO}_{3}+\mathrm{CaHPO}_{4} \rightarrow \beta-\mathrm{Ca}_{3}\left(\mathrm{PO}_{4}\right)_{2}+\mathrm{CO}_{2}+\mathrm{H}_{2} \mathrm{O}
$$

Não é possível formar-se o $\beta$-TCP por precipitação de soluções aquosas, e através da calcinação de ossos pode-se obter o $\beta$-TCP com íons substituídos (Zavaglia, 2011). Segundo Chow (1991) e Driessens et al (1997), o beta fosfato tricálcico também pode ser usado em 
cimentos de fosfato de cálcio, materiais biocompatíveis com grandes aplicações na área biomédica e que endurecem ou pegam no sítio de implantação.

Ao ser combinado com hidroxiapatita, o $\beta$-TCP forma o BCP, um fosfato de cálcio bifásico. Assim como o $\beta$-TCP, o BCP é uma cerâmica muito usada na substituição de tecidos ósseos. O beta fosfato tricálcico também pode ser utilizado, em pequenas quantidades, em complexos vitamínicos e como agente de polimento em cremes dentais (Dorozhki, 2009).

\section{METODOLOGIA}

O beta fosfato tricálcico foi obtido através da mistura a úmido de carbonato de cálcio $(0,35 \mathrm{~mol})$ e fosfato bibásico de cálcio $(0,70 \mathrm{~mol})$, utilizando-se acetona como solvente.

A mistura foi realizada manualmente, por 30 minutos e, posteriormente, deixou-se a solução descansar por cerca de $24 \mathrm{~h}$. O precipitado foi seco em uma estufa por três horas a $80^{\circ} \mathrm{C}$.

O pó obtido de beta-TCP foi desaglomerado em um almofariz de ágata e dividido em duas frações, que em seguida foram calcinadas em duas temperaturas diferentes $\left(950^{\circ} \mathrm{C} \mathrm{e}\right.$ $1050^{\circ} \mathrm{C}$ ), durante seis horas.

As frações do material foram então submetidas à análise por espectroscopia de infravermelho por transformada de Fourier (FTIR) e difração de raios X (DRX). Este último método identificou as fases cristalinas do beta-TCP. A análise foi conduzida a temperatura ambiente em um equipamento Shimadzu XRD-6000 a $40 \mathrm{kV}$ e $30 \mathrm{~mA}$ e com um comprimento de onda $\lambda \mathrm{CuK} \alpha=0.154 \mathrm{~nm}$. As amostras em forma de pó foram analisadas em um intervalo de varredura de $2 \theta$ entre 20 e 80 graus a uma taxa de $1,2^{\circ} / \mathrm{min}$.

\section{RESULTADOS E DISCUSSÕES}

\subsection{Resultados dos ensaios de FTIR}

A partir dos espectros de absorção no infravermelho obtidos para as amostras de betaTCP calcinada a $950^{\circ} \mathrm{C}$ (Figura 1) e $1050^{\circ} \mathrm{C}$ (Figura 2), é possível verificar a presença de impurezas.

Os picos em torno de 963,1024 e $1087 \mathrm{~cm}^{-1}$, representam o grupamento $\mathrm{PO}_{4}^{-3}$, que ficam mais evidentes com a sinterização; a banda em $3576 \mathrm{~cm}^{-1}$ representa o grupamento $\mathrm{OH}^{-}$. Os espectros também mostram grande quantidade de $\mathrm{CO}_{3}^{-2} \mathrm{em} 1411 \mathrm{~cm}^{-1}$, que diminui com o aumento da temperatura de calcinação. 
Figura 1 - Espectro da amostra de beta-TCP calcinado a $950^{\circ}$.C.

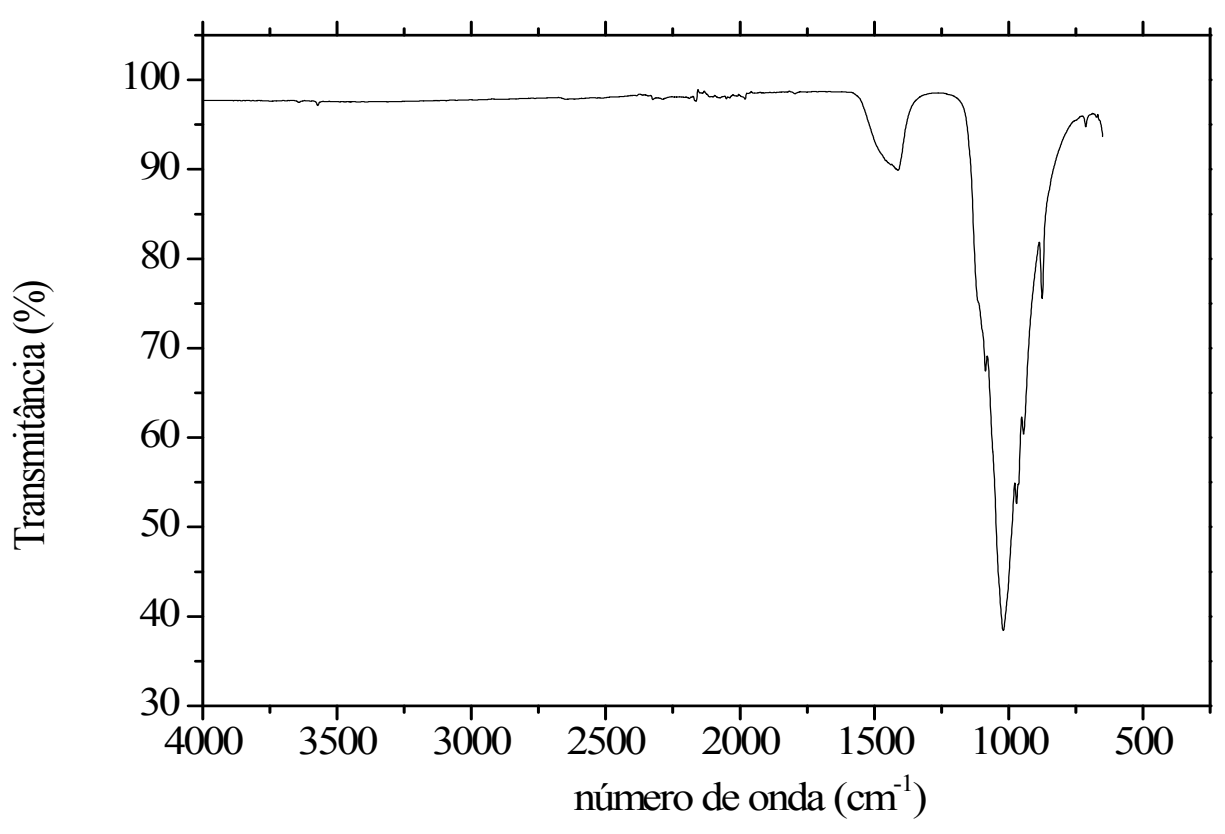

Figura 2 - Espectro da amostra de beta-TCP calcinado a $1050^{\circ} \mathrm{C}$.

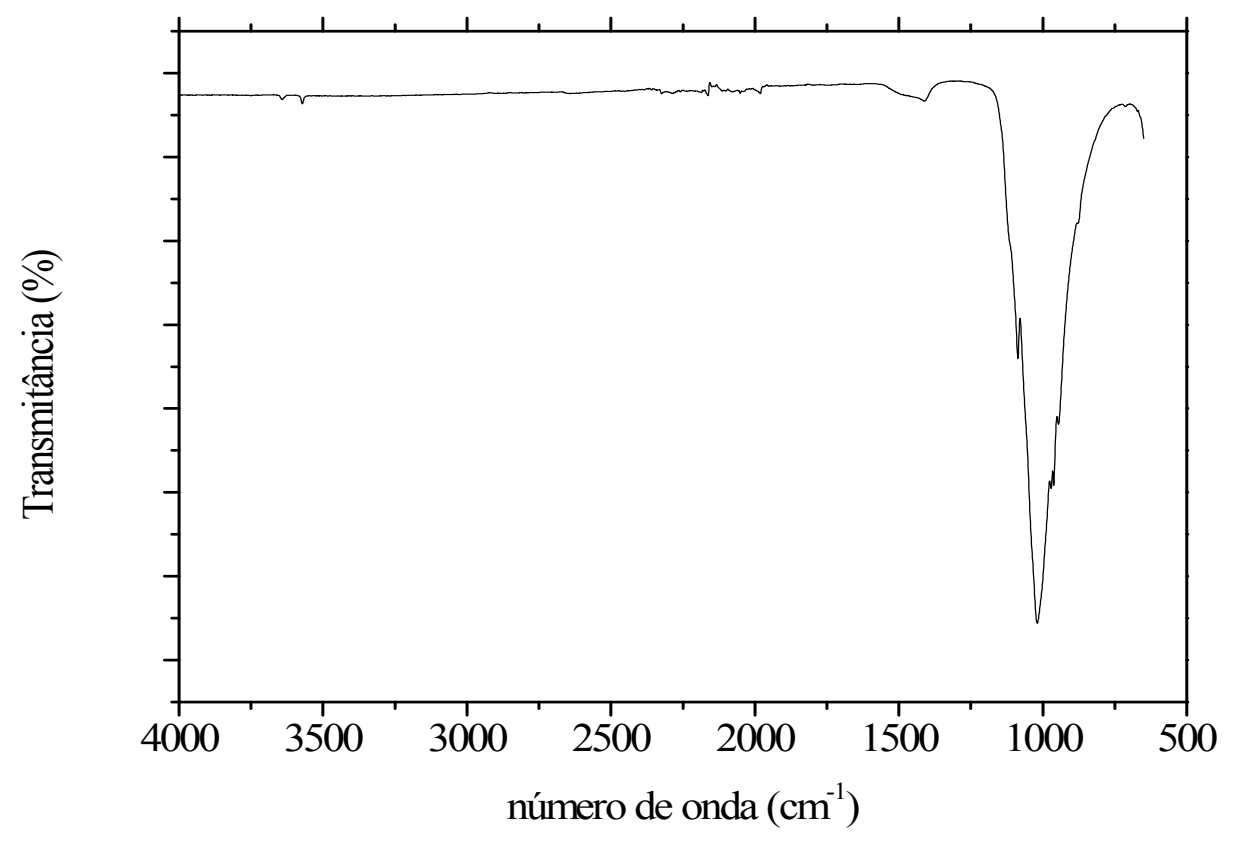




\subsection{Resultados dos ensaios de DRX}

Os difratogramas de raios-X do beta-TCP calcinados em diferentes temperaturas, são mostrados nas Figuras 3 e 4.

Figura 3 - Difratograma da amostra de beta-TCP calcinado a $950^{\circ} \mathrm{C}$.

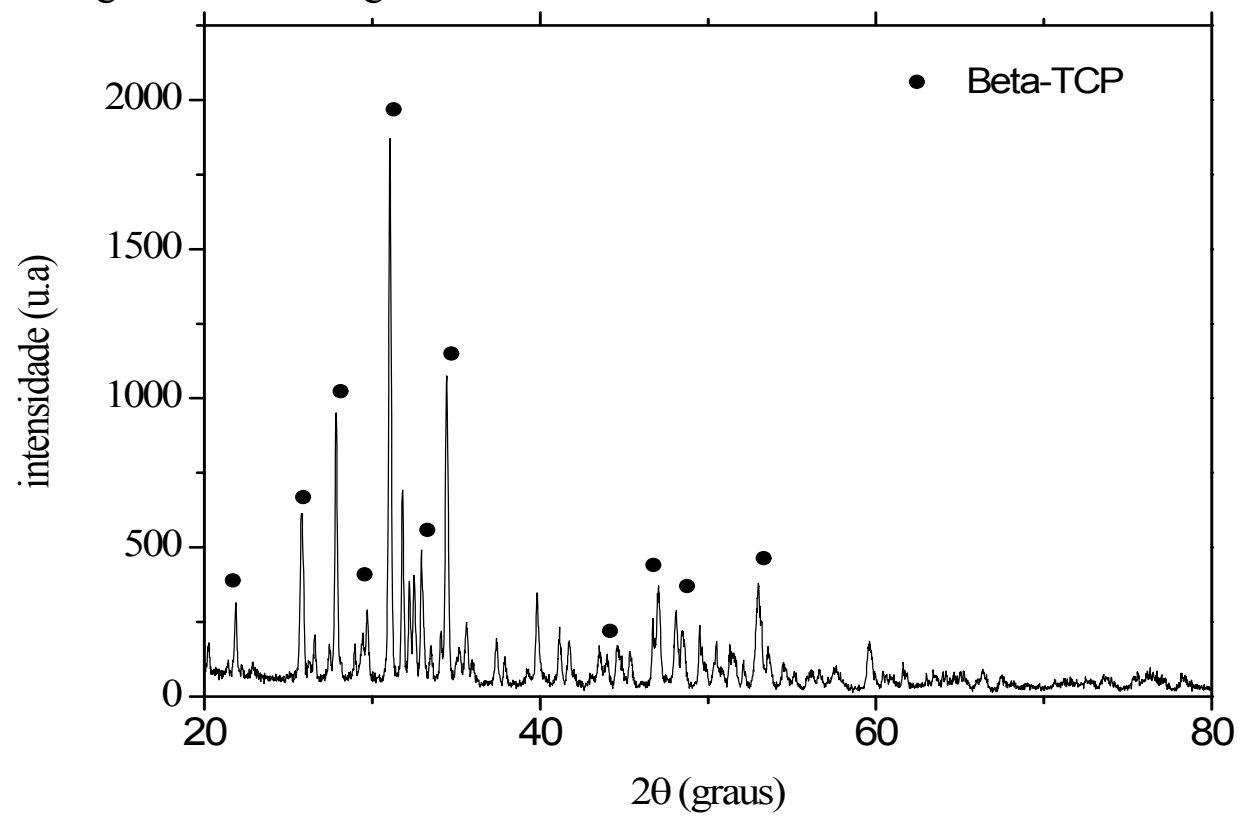

Figura 4 - Difratograma da amostra de beta-TCP calcinado a $1050^{\circ} \mathrm{C}$

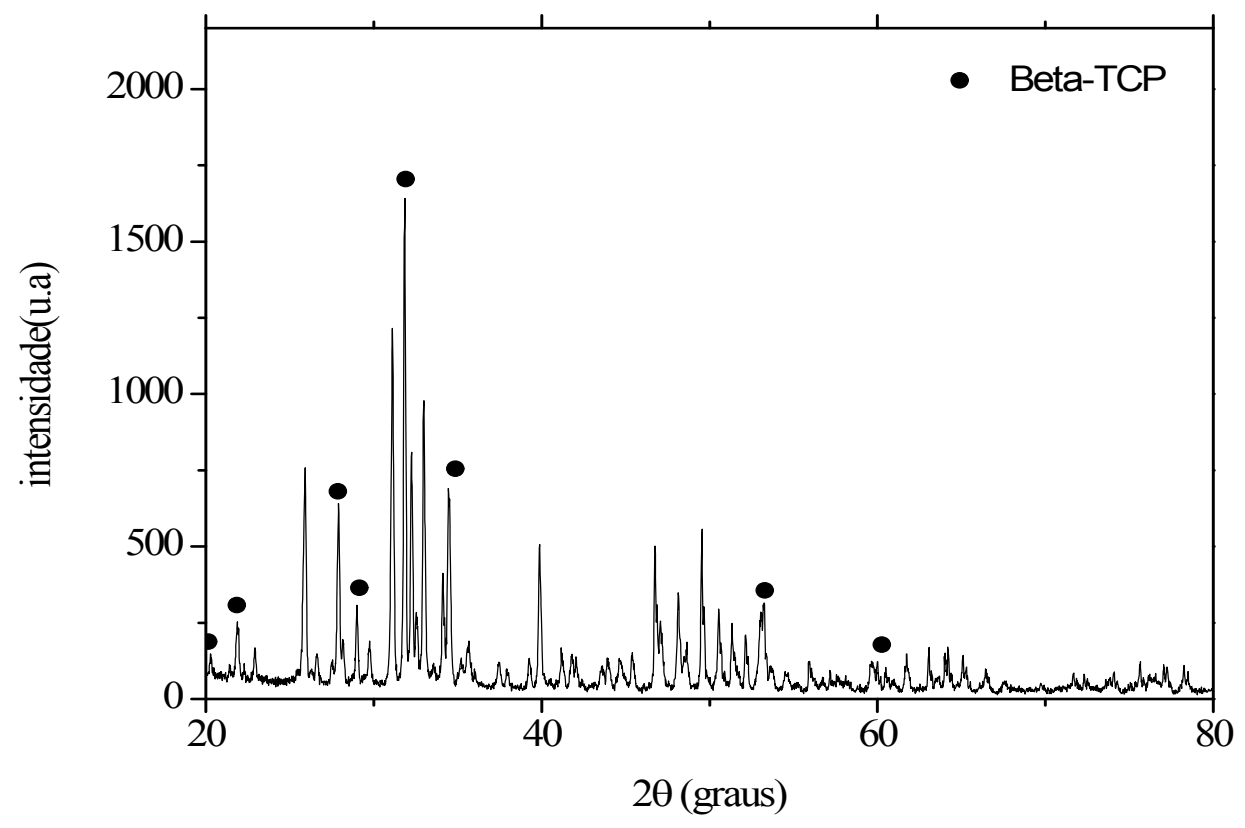




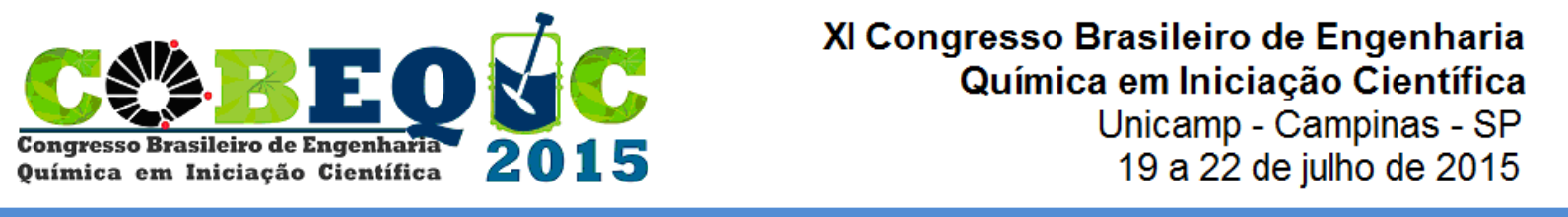

Pelos difratogramas obtidos (Figura 3 e Figura 4) é possível ver a presença de outras fases além da fase do beta-TCP.

\section{CONCLUSÃO}

A síntese de $\beta$-TCP pelo método utilizado deu origem a um pó com impurezas, devido à presença de carbonato identificado nos espectros de infravermelho. Isso pode ser devido a ineficiência da mistura manual ou em função da temperatura de $950^{\circ} \mathrm{C}$ ser baixa demais para a síntese do biomaterial, já que a sinterização na temperatura de $1050^{\circ} \mathrm{C}$ produziu um biomaterial mais puro devido a considerável diminuição da banda, correspondente ao carbonato, no espectro de infravermelho e o aumento da cristalinidade indicado pelos ensaios de DRX.

\section{REFERÊNCIAS}

CHOW, L. C.; Development of self-setting calcium phosphate cements. J. Ceram. Soc. Jap., v. 99 (10), p. 954-964, 1991.

DOROZHKI, S. V. Calcium orthophosphates in nature, biology and medicine. Materials, v. 2 p. 399-498, 2009.

DRIESSENS, F. C. M; FERNANDEZ, E.; GINEBRA, M. P.; BOLTONG, M. G.; PLANELL, J. A.; Calcium phosphates and ceramic bone cements vs. acrylic cements. Anal. Quim. Int. Ed., v. 93, p. S38-S43, 1997.

GOUVEIA, D. S.; Obtenção de Pós Nanométricos de Hidroxiapatita Sintetizados com Magnésio Utilizando Ultra-Som. Tese de Doutorado - Instituto de Pesquisas Energéticas e Nucleares, Universidade de São Paulo, São Paulo. 2008.

RYU, H. S.; YOUN, H. J.; HONG, K. S.; CHANG, B. S.; LEE, C. K.; CHUNG, S. S. An Improvement in Sintering Property of $\beta$-tricalcium Phosphate by Addition of Calcium Pyrophosphate. Biomaterials, v.23, p. 909-914, 2002.

ZAVAGLiA, F. C.; Síntese, Caracterização e Processamento de Beta Fosfato Tricálcico para Manufatura de Implantes Personalizados. Dissertação de MestradoDepartamento de Engenharia de Materiais, Universidade Estadual de Campinas, Campinas. 2011. 